\title{
Evidence-based approach to the treatment of hidradenitis suppurativa/acne inversa, based on the European guidelines for hidradenitis suppurativa
}

\author{
Wayne Gulliver $^{1,2}$ • Christos C. Zouboulis ${ }^{1,3}$ • Errol Prens ${ }^{1,4}$ • Gregor B. E. Jemec ${ }^{1,5}$ • \\ Thrasivoulos Tzellos ${ }^{1,6}$
}

Published online: 1 February 2016

(C) The Author(s) 2016. This article is published with open access at Springerlink.com

\begin{abstract}
Hidradenitis suppurativa/acne inversa (HS) is a chronic inflammatory skin disease characterized by painful, recurrent nodules and abscesses that rupture and lead to sinus tracts and scarring. To date, an evidence-based therapeutic approach has not been the standard of care and this is likely due to the lack of evidence based treatment guidelines. The purpose of this study was to promote a holistic evidence-based approach which implemented Level of Evidence and Strength of Recommendation for
\end{abstract}

Wayne Gulliver

WGulliver@newlabresearch.com

Christos C. Zouboulis

christos.zouboulis@klinikum-dessau.de

Errol Prens

e.prens@erasmusmc.nl

Gregor B. E. Jemec

gbj@regionsjaelland.dk

Thrasivoulos Tzellos

ltzellos@googlemail.com

1 European Hidradenitis Suppurativa Foundation e.V, Dessau, Germany

2 Faculty of Medicine, Memorial University of Newfoundland, St. John's, Newfound land \& Labrador, Canada

3 Departments of Dermatology, Venereology, Allergology and Immunology, Dessau Medical Center, Dessau, Germany

4 Department of Dermatology, Erasmus MC, Rotterdam, The Netherlands

5 Department of Dermatology, Roskilde Hospital, Health Sciences Faculty, University of Copenhagen, Copenhagen, Denmark

6 Department of Dermatology, Faculty of Health Sciences, University Hospital of North Norway, Harstad, Troms, Norway the treatment of HS. Based upon the European Dermatology Forumguidelines for the management of HS, evidencebased approach was explored for the treatment of HS. The diagnosis of HS should be made by a dermatologist or other healthcare professional with expert knowledge in HS. All patients should be offered adjuvant therapy as needed (pain management, weight loss, tobacco cessation, treatment of super infections, and application of appropriate dressings). The treating physician should be familiar with disease severity scores, especially Hurley staging, physician global assessment and others. The routine use of patient'reported outcomesincluding DLQI, itch and pain assessment (Visual Analogue Scale) is strongly recommended. The need for surgical intervention should be assessed in all patients depending upon type and extent of scarring, and an evidence-based surgical approach should be implemented. Evidence-based medical treatment of mild disease consists of topical Clindamycin $1 \%$ solution/gel b.i.d. for 12 weeks or Tetracycline 500 p.o. b.i.d. for 4 months (LOE IIb, SOR B), for more widespread disease. If patient fails to exhibit response to treatment or for a PGA of moderate-to-severe disease, Clindamycin 300 p.o. b.i.d. with Rifampicin 600 p.o. o.d. for 10 weeks (LOE III, SOR C) should be considered. If patient is not improved, then Adalimumab $160 \mathrm{mg}$ at week $0,80 \mathrm{mg}$ at week 2 ; then $40 \mathrm{mg}$ subcutaneously weekly should be administered (LOE Ib, SOR A). If improvement occurs then therapy should be maintained as long as HS lesions are present. If the patient fails to exhibit response, then consideration of second or third line therapy is required. A growing body of evidence is being published to guide the treatment of HS. HS therapy should be based upon the evaluation of the inflammatory components as well as the scarring and should be directed by evidence-based guidelines. Treatment should include surgery as well as medical 
treatment. Future studies should include benefit risk ratio analysis and long term assessment of efficacy and safety, in order to facilitate long term evidence based treatment and rational pharmacotherapy.

Keywords Hidradenitis suppurativa · Medical therapy · Surgical therapy $\cdot$ Evidence-based dermatology $\cdot$ Guidelines

\section{Introduction}

Hidradenitis suppurativa/acne inversa (HS) is a chronic inflammatory skin disease characterized by painful, recurrent nodules and abscesses that rupture and lead to the formation of sinus tracts and scarring. HS has a psychologically meaningful and clinically significant negative effect on the patient's quality of life. It is fairly common, affecting approximately $1 \%$ of the population. Experience indicates that the patients are only diagnosed after long delays. This may be due to the previous orphan status of the disease. It is further speculated that an evidence-based therapeutic approach has therefore not been the standard of care to date. This status is likely reinforced by the lack of evidence based treatment guidelines. Based upon the Guidelines for HS treatment produced by the European Dermatology Forum [1], we are suggesting an evidence-based approach that includes Level of Evidence (LOE) and Strength of Recommendation (SOR) to produce a comprehensiveand rational approach for this debilitating and devastating chronic recurrent inflammatory disorder of the skin.

\section{Definition}

HS is a chronic, inflammatory, recurrent, debilitating skin disease of the hair follicle that usually presents after puberty with painful, deep-seated, inflamed lesions in the body folds, most commonly the axillae, inguinal and anogenital regions, but can affect other areas as well (modified, Dessau definition, 1st International Conference on Hidradenitis suppurativa/Acne inversa, March 30-April 1, 2006, Dessau, Germany) [2, 3].

\section{Epidemiology}

Studies which provide prevalence or incidence estimations have been performed under different settings (hospital versus population-based) and in different time periods. In addition, the applied diagnostic methods are varying (selfreported, medically assessed, diagnosis of treatments codes through automated requests in medical information systems) and, therefore, they led to an important variability regarding the prevalence of HS [4].
Using a health claims database, HS prevalence was estimated to be $0.05 \%$ in the USA [5]. The authors reported that selection bias may have influenced results, since they included only health-insured subjects and, therefore, this prevalence rate may not be representative for the general US population. There may also be a classification bias as HS cases were only identified through drug reimbursement, leading to potential underestimations. Further analysis of the data implies important differences in the populations identified. The mean age of US cases was 38 years, i.e. older than the mean age of HS patients in European studies. Hence, young patients who have not asked for medical advice yet, may have been missed.

Two European studies have reported a prevalence of $1 \%$ $[6,7]$. The first was a French population-based investigation on self-declared cases in a representative sample of the French population $(10,000)[6]$. Even though selection bias is unlikely in this setting, a classification bias is likely due to selfdeclaration leading to potential over-estimation of the prevalence rate. Jemec et al. [7] assessed a sample of 599 Danish, clinically examined, unselected subjects and found a prevalence of $1 \%$ (confidence intervals 0.4-2.2). Using a validated questionnaire in a population sample of 16404 persons a possible prevalence of $2.1 \%$ was suggested. In another study, Jemec found a prevalence of $4 \%$ in young adult women [8]. As HS is mainly a disease of young adults with a female predominance, this result is not discordant with the figure of $1 \%$ in the general population. These results are in discrepancy with the reported equal male to female ratio of the previous prospective study of the same authors [7].

The mean incidence of HS was assessed to be 6.0 per 100 , 000 person-years, evaluated through the Rochester Epidemiologic Project in an American county (Minnesota) with a population of about 144,000. Between 1968 and 2008 a two-fold incidence was calculated (4 to 10 per 100,000 person-years). This increase may be due to an increase in detection and coding of HS in the medical information system. The limitation of the study is its retrospective design. Moreover, a selection bias could have occurred due to recruitment through medical information system leading to a possible underestimation of incidence, since extrapolation of the data leads to the low prevalence of $0.08-0.20 \%$ [9]. There also may be a classification bias due to missed diagnosis of mild early cases.

The discrepancies between European and American studies may be due to different methodologies but may also reflect actual differences in prevalence/incidence of HS or different diagnostic criteria with only the most severe cases having been reported in the USA.

\subsection{HS in children and adolescents}

Data regarding HS in children and adolescents are scarce. HS can be seen in prepubertal age. Only $2 \%$ of cases occur before the age of 11 years [10]. In a retrospective study of 855 
patients, $7.7 \%$ reported an onset of HS before the age of 13 years [11]. Early onset HS was associated with stronger genetic susceptibility and more widespread disease [11]. Recommendations for treatment in this age group are based only on case reports and extrapolation of treatments evaluated in clinical trials in adult population [12]. Finasteride, an antiandrogen, has been evaluated in a case series of early onset HS [13]. Most patients had endocrine co-morbidities, like polycystic ovary syndrome and precocious puberty. In all patients, finasteride, combined with antibiotics or other treatment modalities, facilitated remission and improved disease severity. Finasteride is recommended, especially in patients with refractory HS or with endocrine co-morbidities. Careful assessment of benefits and risks with its use is crucial in this age group.

Topical clindamycin twice daily for 3 months should be considered as first-line treatment option in mild to moderate HS. Systemic clindamycin plus rifampicine and tetracycline can be used, taking into careful account age restrictions, dosing differences, and possible side effects. Analgesics and corticosteroids can be considered to control pain and reduce inflammation. Adjuvant therapy and timely treatment of superinfections are essential. Scarring and Hurley III severity should be treated with surgical procedures. Negative pressure wound therapy in $30 \mathrm{HS}$ patients (mean age 16 years) from a retrospective case series provide evidence that more $87 \%$ of patients had successful outcomes with only 4 patients discontinuing because of side effects [14].

\section{Disease assessment}

Objective disease assessment is a pre-requisite for the development of evidence based therapy. The Hurley classification of disease severity is the oldest and most commonly used of the several systems that have been suggested. The Hurley score is however a static score and not sufficiently responsive to change, particularly relating to the inflammatory component of HS [1]. In the past, the method of assessment was the Sartorius Scores, but in recent clinical research this has not been used as the primary endpoint. A newly developed physician rated assessment is the Hidradenitis Suppurativa Clinical Response (HiSCR) developed and validated and used as the primary endpoint in randomized control trials studying the use of adalimumab [15]. The HiSCR is not only a valid and meaningful endpoint for assessing HS treatment effectiveness in the inflammatory component of HS, but also its testretest reliability, convergent validity, responsiveness and predictive validity were confirmed. The HiSCR is also significantly correlated with improvements in all physician-related measures (Hurley Stage, modified Sartorius Scores and HS Physicians Global Assessment), and patient reported outcomes (visual analogue pain scale, dermatology life quality index and work productivity and activity impairment questionnaire). HiSCR has been used to study the effect of adalimumab in HS and patients who continue responsiveness had significant improvements in both physician-related and patient-reported HS disease severity and impact [15].

\section{Methods}

Based upon the recently published guidelines for hidradenitis suppurativa developed by the Guidelines Subcommittee of the European Dermatology Forum [1], a detailed review of all therapies was conducted. All therapeutic aspects of the treatment included in the Guidelines were reviewed and a category of evidence and strength of recommendation was developed for the first line therapy (see Table 1) which included topical Clindamycin, oral Clindamycin/Rifampicin, tetracycline and subcutaneous Adalimumab. A similar approach was taken for the second line therapies which included Zinc Gluconate, Resorcinol, Intralesional Corticosteroids, Infliximab, Acitretin and Etretinate. Third line therapies evaluated include Colchicine, Botulinum Toxin, Isotretinoin, Dapsone, Cyclosporine, hormones. Surgical therapies evaluated included excision or curettage of individual lesions, total excision of lesions surrounding hair-bearing skin, secondary intention healing, primary closure, reconstructive with skin grafting and NPWTreconstruction with flap, deroofing, carbon dioxide laser therapy, Nd:YAG laser therapy andintense pulsed light (IPL). Other aspects of treatment that were assessed include pain control and dressings (see Table 1). Based upon the Category of Evidence and Strength of Recommendation, an algorithm incorporating all aspects of HS therapy was developed (see Fig. 1). All therapeutic aspects with respect to HS therapy included in the Guidelines were assessed using the Grading of Recommendations Assessment and Evaluation (GRADE) methodology (see Table 2) [16]. At least 2 of the authors rated the medical and surgical treatments contained in the Guidelines.

\subsection{First-line treatment options}

\subsubsection{Topical clindamycin}

Clindamycin lotion $1 \%$ is the only antibiotic that has been studied as topical agent. Its efficacy has been described in a double-blind, placebo-controlled, randomized trial in HS patients with Hurley stage I or mild stage II [17]. It is recommended as first line treatment option in patients with mild HS-PGA or localized Hurley I/mild Hurley II stage, especially when there are no deep inflammatory lesions (abscesses). The proposed dosing regimen is twice daily, for 3 months. If clinical response is not achieved after that treatment period, other treatment options must be considered (LOE IIb; SOR B). 
Table 1 Category of Evidence/ Strength of Recommendation Rating Scale

\begin{tabular}{|c|c|c|}
\hline Therapy & $\begin{array}{l}\text { Category of } \\
\text { Evidence }\end{array}$ & $\begin{array}{l}\text { Strength of } \\
\text { Recommendation }\end{array}$ \\
\hline \multicolumn{3}{|l|}{ 1st Line } \\
\hline Clindamycin (topical) ${ }^{1}$ & $\mathrm{IIb}$ & Possible B \\
\hline Clindamycin/Rifampicin (oral) ${ }^{2}$ & III & $\mathrm{C}$ \\
\hline Adalimumab (subcutaneous) ${ }^{3}$ & $\mathrm{Ib}$ & A \\
\hline Tetracycline (oral) & $\mathrm{IIb}$ & $\mathrm{B}$ \\
\hline \multicolumn{3}{|l|}{ Surgery } \\
\hline Excision or Curettage of Individual Lesions & III & $\mathrm{C}$ \\
\hline Total Excision of the Lesions and Surrounding Hair-Bearing Skin & $\mathrm{IIb}$ & $\mathrm{B}$ \\
\hline Second Intention Healing & $\mathrm{IIb}$ & $\mathrm{B}$ \\
\hline Primary Closure & III & $\mathrm{C}$ \\
\hline Reconstruction with Skin Grafting \& NPWT & III & $\mathrm{C}$ \\
\hline Reconstruction with Flap Plasty & $\mathrm{Ia} / \mathrm{IIa}$ & $\mathrm{A} / \mathrm{B}$ \\
\hline Deroofing & IV & $\mathrm{D}$ \\
\hline Carbon Dioxide Laser Therapy & $\mathrm{Ib}$ & A \\
\hline Nd:YAG Laser & $\mathrm{Ib}$ & A \\
\hline IPL & IV & $\mathrm{D}$ \\
\hline \multicolumn{3}{|l|}{ 2nd Line } \\
\hline Zinc Gluconate & III & $\mathrm{C}$ \\
\hline Resorcinol & III & $\mathrm{C}$ \\
\hline Intralesional Corticosteroids & IV & $\mathrm{D}$ \\
\hline Systemic Corticosteroids & IV & $\mathrm{D}$ \\
\hline Infliximab & $\mathrm{Ib} / \mathrm{IIa}$ & $\mathrm{B}$ \\
\hline Acitretin/Etretinate & III & $\mathrm{C}$ \\
\hline \multicolumn{3}{|l|}{ 3rd Line } \\
\hline Colchicine & IV & $\mathrm{D}$ \\
\hline Botulinum Toxin & IV & $\mathrm{D}$ \\
\hline Isotretinoin & IV & $\mathrm{D}$ \\
\hline Dapsone & IV & $\mathrm{D}$ \\
\hline Cyclosporine & IV & $\mathrm{D}$ \\
\hline Hormones & IV & $\mathrm{D}$ \\
\hline \multicolumn{3}{|l|}{ Pain Control } \\
\hline NSAIDS & IV & $\mathrm{D}$ \\
\hline Opiates & IV & $\mathrm{D}$ \\
\hline \multicolumn{3}{|l|}{ Dressings } \\
\hline $\begin{array}{l}\text { No studies have been published to date on the use of specific dressing or } \\
\text { wound care methodology in HS. Choice of dressing is based on clinical } \\
\text { experience. }\end{array}$ & IV & $\mathrm{D}$ \\
\hline
\end{tabular}

1. Single double-blind, placebo-controlled, randomized trial. Hurley stage 1-2.

2. Evaluated in case series.

3. Multiple prospective randomized, double-blind, placebo-controlled trials (Pioneer 1 and 2).

\subsubsection{Systemic antibiotics}

Tetracycline Tetracycline $500 \mathrm{mg}$ b.i.d. has been tested and compared with topical clindamycin in a double-blind, randomized, controlled trial [18]. No significant difference was detected between the two treatment modalities. Tetracycline $500 \mathrm{mg}$ b.i.d. is recommended as first line treatment option in patients with moderate HS-PGA or more widespread Hurley
I/mild Hurley II stage, especially when there are no deep inflammatory lesions (abscesses), for up to 4 months. If clinical response is not achieved after that treatment period, other treatment modalities must be considered (LOE IIb; SOR B).

CLINDAMYCIN/RIFAMPICIN Clindamycin $300 \mathrm{mg}$ b.i.d. in combination with rifampicin $600 \mathrm{mg}$ once daily or $300 \mathrm{mg}$ b.i.d. has been evaluated in several case series [19]. 
Establish Diagnosis of HS made by Dermatologists or other

healthcare professional with expert knowledge in HS

Adjuvant therapy (Pain Management, Weight Loss and Tobacco Abstinence /Treatment of Super Infections/ Appropriate Dressings)

Stage Hurley I - III / Disease Activity: HiSCR, PGA, Sartorius Score / Patient Reported Outcomes: DLQI / Pain Assessment

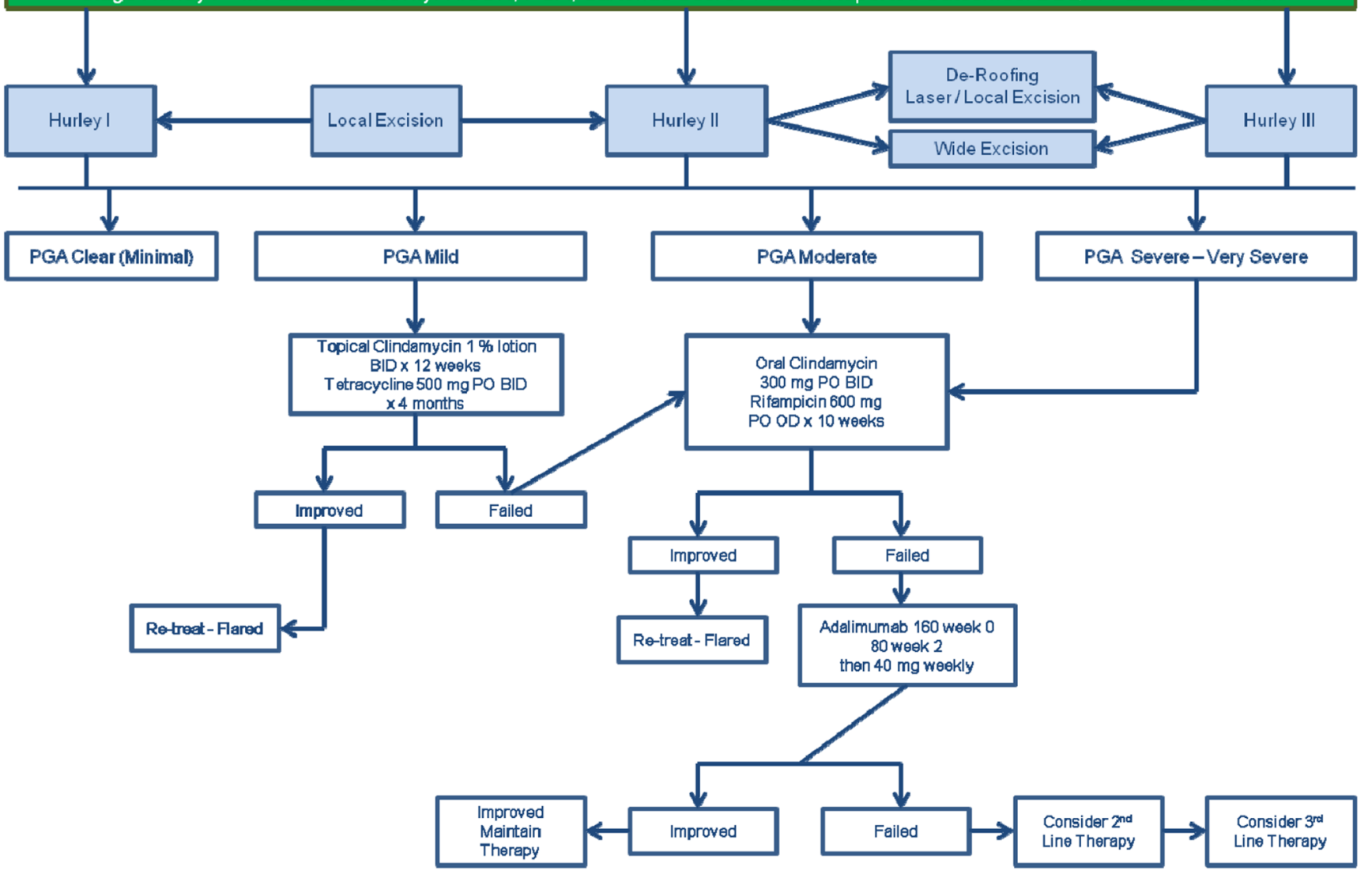

Fig. 1 Algorithm

This treatment combination is recommended as first-line treatment option in patients with moderate and severe HS-PGA or Hurley II stage, up to 10 weeks. If clinical responses not achieved after that treatment period, other treatment modalities must be considered (LOE III; SOR C).

\subsubsection{Biologic agents}

Adalimumab Adalimumab sc $40 \mathrm{mg}$ weekly, has been evaluated in a prospective, randomized, double-blind, placebocontrolled trial [20]. It influenced positively not only the primary outcome (HiSCR), but also pain (VAS pain score), DLQI and work productivity (TWPI score). Adalimumab is recommended as first-line treatment option in patients with moderate to severe HS who were unresponsive or intolerant to oral antibiotics. It should be administered as $160 \mathrm{mg}$ at week $0,80 \mathrm{mg}$ at week 2 and $40 \mathrm{mg}$ each week thereafter, starting from week 4.If clinical response with HiSCR is not achieved after 16 weeks of treatment, other treatment modalities must be considered (LOE Ib; SOR A) [21]. A preliminary report from a subsequent RCT supports the validity of the findings.

\subsection{Second-line treatment options}

\subsubsection{Biologic agents}

Infliximab Infliximab $5 \mathrm{mg} / \mathrm{kg}$ has been evaluated in a randomized, placebo-controlled, cross-over trial [22]. No significant difference in the $>50 \%$ improvement was detected (primary end point), while a significantly higher 25-50\% improvement rate was detected along with positive influence in DLQI and VAS pain score. Infliximab $5 \mathrm{mg} / \mathrm{kg}$ at week $0,2,6$ and every 2 months thereafter for 12 weeks is recommended in patients with moderate to severe HS as second-line treatment option, only after failure of adalimumab. If clinical response is not achieved after 12 weeks of treatment, other treatment modalities must be considered (LOE IIa; SOR B). 
Table 2 Category or Evidence Strength of Recommendation Rating Scale

\begin{tabular}{lc}
\hline Category of Evidence & Strength of Recommendation \\
\hline $\begin{array}{l}\text { Ia: Meta-analysis of randomized controlled trials } \\
\text { Ib: Randomized controlled trial }\end{array}$ & A: Category I evidence \\
$\begin{array}{l}\text { IIa: Controlled study without randomization } \\
\text { IIb: Quasi-experimental study }\end{array}$ & $\begin{array}{c}\text { B: Category II evidence or extrapolated from } \\
\text { category I evidence }\end{array}$ \\
$\begin{array}{l}\text { III: Non-experimental descriptive studies such as comparative, } \\
\text { correlation and case-control studies }\end{array}$ & $\begin{array}{c}\text { C: Category III evidence or extrapolated from } \\
\text { category I or II evidence }\end{array}$ \\
$\begin{array}{l}\text { IV: Expert committee reports or opinion or clinical experience } \\
\text { of respected authorities, or both }\end{array}$ & $\begin{array}{c}\text { Dategory IV evidence or extrapolated from } \\
\text { category II or III evidence }\end{array}$ \\
\hline
\end{tabular}

Guyatt G, Oxman AD, et al. GRADE: An emerging consensus on rating quality of evidence and strength of recommendations. BMJ April 2008; 336: 924. Last accessed February 2014.
Surgical treatment Since non-surgical methods rarely result in lasting cure, surgical treatment is a quite common and accepted therapeutic modality for HS [1]. Surgical studies with classical evidenced-based evaluation of efficacy are generally sparse [23]. In agreement with the evidence paradigm of surgery, only large case series and studies reporting recurrence rates and a follow-up period of at least 1-year were therefore included in the evaluation.

\subsection{Radical surgical excision}

Five studies looking at the role of radical excision (LOE IIb, SOR B) [24-28]. The type of surgery and margins were selected based on the body region and severity of the disease. A statistically significant relationship was shown between the efficacy of a procedure and the number and severity of body areas affected. The width of the excision and not the wound closure technique influenced the therapeutic outcome [25, 27, 29], whereas vacuum-assisted closure may accelerate the timepoint of a delayed primary closure as shown by a retrospective study [30]. On the other hand, secondary intention healing revealed "good' or "excellent" results in $27.3 \%$ and $39.4 \%$, respectively, of 97 cases studied after 12 months of follow-up [31]. Buimer et al. [24] observed $41 \%$ recurrences in 200 patients treated with radical surgery and closed by primary closure or skin graft. Bieniek et al. [25] described a complete recovery $59.7 \%$ of 57 patients with 118 sites during a 2-year follow-up period. Bohn and Svensson [26] described the results of radical excision among 138 patients and follow-up from 3 to 21 years. In 38 of 116 skin-grafted patients $(32.8 \%)$ who completed a questionnaire, the disease recurred to some degree, and 14 of them required further operation. Van Rappard et al. [27] also experienced a $34 \%$ recurrence rate in 92 primary closed surgically treated sites after 1-5 years follow-up. In contrast, Rompel and Petres [28] performed radical wide excision in 106 patients with a median postoperative follow-up time of 36 months and only a $2.5 \%$ rate of recurrence within operated fields and wound infection in $3.7 \%$ of patients. A retrospective study of 106 patients treated with radical excision, whereas 100 wounds were primary closed, 29 resurfaced with split skin grafts and 14 with local, fasciocutaneous or musculocutaneous flaps revealed $69.9 \%$ recurrences after primary closure and no recurrences in the 'graft' and the 'flap' series [32]. In another retrospective study, 31 patients undergoing drainage procedures, limited regional surgery, and radical wide excisions confirmed the therapeutic advantage of radical excision showing $100 \%$ recurrence after drainage, $42.8 \%$ recurrence after limited excision, and $27 \%$ recurrence after radical excision ( $p<0.05$; mean follow-up period 72 months) [33]. Similar results were reported by Wiltz et al. [34] in 43 patients with perianal involvement.

\subsection{Deroofing and skin-tissue-saving excision with electrosurgical peeling (STEEP)}

An open study (SOR B) by van der Zee et al. [35] explored the efficacy of deroofing in 73 lesions; $83 \%$ showed no recurrence during a median follow-up period of 34 months, and $17 \%$ showed recurrence after a median follow-up period of 4.6 months. Postoperative bleeding in 1 patient was the only reported adverse event, and $90 \%$ of patients responded that they would recommend the procedure to other individuals with HS. Blok et al. [36] evaluated retrospectively 113 patients, who underwent 482 operations (363 primary operations and 119 re-operations) with deroofing or STEEP. Relapses occurred after $29.2 \%$ of primary operations in an average follow-up period of 43 months.

\subsection{Carbon dioxide LASER}

Results of studies present controversial findings regarding the use of carbon dioxide LASER surgery in HS (LOE Ib, SOR A). Scanner assisted carbon dioxide LASER treatment under topical anesthesia was evaluated in a retrospective clinical study with 61 HS patients and 185 involved areas. A total number of 154 sessions led to a $1.1 \%$ recurrence in a follow-up period of 1-19 years [37]. In most articles, healing by secondary intention was used. In another retrospective follow-up study in 34 patients with initial Hurley II stage, who were contacted by telephone after surgery for follow-up 
information, a mean healing time of 4 weeks was assessed with a recurrence rate of $11.8 \%$ [38]. However, new lesions (separated from the initial surgical site by $5 \mathrm{~cm}$ ) developed in $35.3 \%$ of the patients, and $73.5 \%$ of the patients had flares in an area other than the treated site. In a recent retrospective study involving 58 patients and the use of $\mathrm{CO} 2$ laser evaporation of lesions in patients with $\mathrm{HS}, 95 \%$ of the patients reported some or great improvement, and $91 \%$ would recommend the CO2 laser surgery. $29 \%$ reported recurrence of HS lesions within the borders of the treated area [39].

\subsection{Nd:YAG LASER}

Based on the assumption that HS starts in the hair follicle, the 1064-nm neodymium-doped yttrium aluminum garnet (Nd:YAG) laser was used in a prospective, randomized, controlled study on 22 patients with stage Hurley II to III HS [40, 41]. A series of 3 monthly laser sessions were performed. Treatment response was measured before each laser session and 1 month after the completion of laser treatment \{HS Lesion, Area, and Severity Index (HS-LASI) scale\}. A modification was made to include symptoms (erythema, edema, pain, and purulent discharge; modified HS-LASI, 0-3 scale]. The percentage change in HS severity after 3 months of treatment was $-65.3 \%$ over all anatomic sites, $-73.4 \%$ inguinal, $-62.0 \%$ axillary, and $-53.1 \%$ inframammary. For all anatomic sites combined and each individual anatomic site, the change in HS severity from baseline to month 3 was statistically significant at the treated sites $(p<.02$ for modified HSLASI and HS-LASI), but not at the control sites $(p>.05$ for modified HS-LASI and HS-LASI) (LOE Ib, SOR A). After 4 monthly sessions, a right-left, treated-untreated comparison revealed an improvement of $72.7 \%$ on the LASER-treated and $22.9 \%$ on the control averaged over all anatomic sites $(p<0.05)[40]$ (LOE Ib, SOR A).

\subsection{Intense pulse light}

A randomized study of $18 \mathrm{HS}$ patients treated at one axilla, groin, or inframammary area with intense pulsed light twice weekly for 4 weeks, whereas the contralateral side received no treatment and served as a control, showed a significant improvement in the meanexamination score that was maintained at 12 months ( $p<0.001$ logistical regression analysis). The improvement was confirmed by independent assessment of clinical photographs (interrater reliability, 0.79; $p<0.001$ ) [42] (LOE IV, SOR D).

\section{BENEFIT-RISK RATIO ANALYSIS}

In order to go from evidence to recommendations that facilitate evidence-based daily clinical practice, the balance of desirable and undesirable outcomes of interest among alternative management strategies is becoming more and more important [43]. Benefit-risk ratio assessment with a structured approach is a becoming an outcome of great importance for authorities during drug regulatory decision-making as well [44].

A structured and appropriate benefit-risk ratio analysis can be performed only for the phase 2 trial of adalimumab, since that is the only randomized controlled trial with a thorough safety analysis [45]. Numbers needed to treat (NNT) for the primary outcome of HiSCR for the phase 2 data at week 16 was 4 (95\% CI: 2.1-10.7) [46], whereas numbers needed to harm $(\mathrm{NNH})$ for any serious adverse event was 26 . This favorable ratio of NNT to $\mathrm{NHH}$, along with the fact that evidence from phase 2 trial indicates positive effect of adalimumab in other outcomes like DLQI, VAS pain score and TWPI, provide the basis to recommend adalimumab as the first-line treatment option in patients with moderate to severe HS who were unresponsive or intolerant to oral antibiotics.

\section{Discussion}

Although we present an evidence-based approach to the diagnosis and treatment of HS, the first and most important step is that a dermatologist or other healthcare professional with expert knowledge in HS assess the patient and make the diagnosis, preferably at an early stage of the disease. Based upon the correct diagnosis and any other significant physical findings, appropriate investigations should be undertaken. HS is a clinical diagnosis and the need for biopsy, laboratory tests, cultures and investigations will be at the discretion of the examining physician and based on patient history and clinical findings. HS may be associated with comorbid diseases such as pyoderma, arthritis, obesity, IBD, anemia, lymphedema and metabolic syndrome [2]. Clinical evidence of any of these associated conditions should be appropriately investigated. Other important comorbid conditions include significant reduction in quality of life, depression, stigmatization and impairment of sexual health $[1,47,48]$. Like the other comorbid diseases this aspect of the disease needs to be assessed and managed appropriately.

Treatment recommendations for the special HS patients' group such as children and adolescents were based only on case reports and extrapolation of clinical data in adults. Emphasis should be given to assessing comorbidities at baseline. There is an obvious need for clinical data of high level to be developed for this patient group.

As part of the holistic/broad-based approach all patients should be offered adjuvant therapy whether it be related to pain management, weight loss, tobacco cessation, treatment of super infections, or implementation of appropriate 
dressings [1]. The treating physician should also be familiar with disease severity scores, especially Hurley staging and Physician Global Assessment. Other disease severity scores that are important include HiSCR and Sartorius scores. Based on the adalimumab study it is suggested that the HS clinical response (HiSCR) [15] is currently the most appropriate clinical endpoint to assess treatment and effectiveness. As mentioned earlier, because of the significant impact on quality of life, patient reported outcomes are extremely important and these should include DLQI as well as pain assessment (Visual Analogue Scale).

With respect to surgical intervention, again this should be assessed in each individual patient and depending upon the type and extent of scarring, surgical procedures such as deroofing, laser, local excision or wide excision may be required.

Benefit-risk ratio structured assessment is needed to evaluate treatments, both short and long term. An initial primary benefit-risk ratio analysis was plausible only for adalimumab, for the first 16 weeks of treatment, which provides evidence of a favorable profile. Real life data from registries along with long term efficacy and safety data from clinical trial extension phases should be evaluated further, to assess long term benefit risk ratio and maintenance of treatment effect, in order to facilitate evidence based long term treatment.

\section{Conclusion}

A growing body of evidence is being published to guide the treatment of HS. HS therapy should be based upon the evaluation of the inflammatory components as well as the scarring and should be directed by evidence-based therapy. Treatment should include surgery as well as medical treatment.

\section{Compliance with ethical standards}

Conflict of interest W Gulliver has received honoraria from AbbVie, Amgen, Celgene, Cipher, Eli Lilly, Galderma, Janssen, Leo, Novartis, Pfizer, Roche, Valeant for participation on advisory boards, consultant services, and speaker engagements. He has also received Grant/Research Support/Clinical Trials from AbbVie, Amgen, Astellas, Celgene, Lilly, Novartis, Pfizer and Regeneron.

CC Zouboulis has received honoraria from AbbVie for participation on ad boards, as a consultant, investigator, and speaker; his department received grants from AbbVie and Novartis for his participation as an investigator.

E Prens has received honoraria from AbbVie, Amgen, Celgene, Janssen, Galderma, Novartis and Pfizer for participation as a speaker, as member of advisory boards and he received investigator-initiated grants (paid to the Erasmus MC) from AbbVie, AstraZeneca, Janssen, and Pfizer.

GBE Jemec has received honoraria from AbbVie, MSD, and Pfizer for participation on advisory boards, and grants from Abbvie, Actelion, Janssen-Cilag, Leo Pharma, and Novartis for participation as an investigator, and received speaker honoraria from AbbVie, Galderma, Leo
Pharma, and MSD. He has furthermore received unrestricted research grants from AbbVie and Leo Pharma.

$\mathrm{T}$ Tzellos has been reimbursed for travel expenses and hotel accommodation to attend dermatologic congresses by Janssen-Cilag, by MSD, and by Novartis. T. Tzellos also participates at the hidradenitis suppurativa advisory board of Abbvie.

Open Access This article is distributed under the terms of the Creative Commons Attribution 4.0 International License (http:// creativecommons.org/licenses/by/4.0/), which permits unrestricted use, distribution, and reproduction in any medium, provided you give appropriate credit to the original author(s) and the source, provide a link to the Creative Commons license, and indicate if changes were made.

\section{References}

1. Zouboulis CC, Desai N, Emtestam L, et al. European S1 guideline for the treatment of hidradenitis suppurativa/acne inversa. J Eur Acad Dermatol Venereol. 2015. doi:10.1111/ jdv. 12966.

2. Fimmel S, Zouboulis CC. Comorbidities of hidradenitis suppurativa (acne inversa). Dermatoendocrinol. 2010;2:9-16.

3. Kurzen H, Kurokawa I, Jemec GB, et al. What causes hidradenitis suppurativa? Exp Dermatol. 2008;17:455-72.

4. Von der Werth JM, Jemec GBE. Morbidity in patients with hidradenitis suppurativa. Br J Dermatol. 2010;144:809-13.

5. Cosmatos I, Matcho A, Weinstein R, et al. Analysis of patient claims data to determine the prevalence of hidradenitis suppurativa in the United States. J Am Acad Dermatol. 2013;68:412-9.

6. Revuz JE, Canoui-Poitrine F, Wolkenstein P, et al. Prevalence and factors associated with hidradenitis suppurativa: results from two case-control studies. J Am Acad Dermatol. 2008;59:596-601.

7. Jemec GB, Heidenheim M, Nielsen NH. The prevalence of hidradenitis suppurativa and its potential precursor lesions. J Am Acad Dermatol. 1996;35:191-4.

8. Jemec GB. The symptomatology of hidradenitis suppurativa in women. Br J Dermatol. 1988;119:345-50.

9. Vazquez BG, Alikhan A, Weaver AL, et al. Incidence of hidradenitis suppurativa and associated factors: a populationbased study of Olmsted county, Minnesota. J Invest Dermatol. 2013;133:97-103.

10. Palmer RA, Keefe M. Early-onset hidradenitis suppurativa. Clin Exp Dermatol. 2001;26:501-3.

11. Deckers IE, van der Zee HH, Boer J, Prens EP. Correlation of earlyonset hidradenitis suppurativa with stronger genetic susceptibility and more widespread involvement. J Am Acad Dermatol. 2015;72: 485-8.

12. Mikkelsen PR, Jemec GB. Hidradenitis suppurativa in children and adolescents: a review of treatment options. Paediatr Drugs. 2014;16:483-9.

13. Randhawa HK, Hamilton J, Pope E. Finasteride for the treatment of hidradenitis suppurativa in children and adolescents. JAMA Dermatol. 2013;149:732-5.

14. Rentea RM, Somers KK, Cassidy L, Enters J, Arca MJ. Negative pressure wound therapy in infants and children: a single-institution experience. J Surg Res. 2013;184:658-64.

15. Kimball AB, Jemec GBE, et al. Assessing the validity, responsiveness and meaningfulness of the hidradenitis suppurativa clinical response (HiSCR) as the clinical endpoint for hidradenitis suppurativa treatment. Br J Dermatol. 2014;171:1434-42. 
16. Guyatt G, Oxman AD, et al. GRADE: an emerging consensus on rating quality of evidence and strength of recommendations. BMJ April. 2008;336:924 Last accessed February 2014.

17. Clemmensen OJ. Topical treatment of hidradenitis suppurativa with clindamycin. Int J Dermatol. 1983;22:325-8.

18. Jemec GB, Wendelboe P. Topical clindamycin versus systemic tetracycline in the treatment of hidradenitis suppurativa. J Am Acad Dermatol. 1998;39:971-4.

19. Gener G, Canoui-Poitrine F, Revuz JE, et al. Combination therapy with clindamycin and rifampicin for hidradenitis suppurativa: a series of 116 consecutive patients. Dermatology. 2009;219:148-54.

20. Kimball AB, Kerdel F, Adams D, et al. Adalimumab for the treatment of moderate to severe hidradenitissuppurativa: a parallel randomized trial. Ann Intern Med. 2012;157:846-55.

21. Jemec GBE 2014 Efficacy and Safety of Adalimumab in Patients with Moderate to Severe Hidradenitis Suppurativa: Results from PIONEER II, a Phase 3, Randomized, Placebo-Controlled Trial. Abstract FC08.2. 22nd Congress of the European Dermatology and Venereology (EADV) Meeting, Amsterdam, Netherlands

22. Grant A, Gonzalez T, Montgomery MO, et al. Infliximab therapy for patients with moderate to severe hidradenitis suppurativa: a randomized, double-blind, placebo-controlled crossover trial. J Am Acad Dermatol. 2010;62:205-17.

23. Rambhatla PV, Lim HW, Hamzavi I. A systematic review of treatments for hidradenitis suppurativa. Arch Dermatol. 2012;148:43946.

24. Buimer MG, Ankersmit MF, Wobbes T, et al. Surgical treatment of hidradenitis suppurativa with gentamicin sulfate: a prospective randomized study. Dermatol Surg. 2008;34:224-7.

25. Bieniek A, Matusiak L, Okulewicz-Gojlik D, Szepietowski JC. Surgical treatment of hidradenitis suppurativa: experiences and recommendations. Dermatol Surg. 2010;36:1998-2004.

26. Bohn J, Svensson H. Surgical treatment of hidradenitis suppurativa. Scand J PlastReconstr Surg Hand Surg. 2001;35:305-9.

27. van Rappard DC, Mooij JE, Mekkes JR. Mild to moderate hidradenitis suppurativa treated with local excision and primary closure. J Eur Acad Dermatol Venereol. 2012;26:898-902.

28. Rompel R, Petres J. Long-term results of wide surgical excision in 106 patients with hidradenitis suppurativa. Dermatol Surg. 2000;26:638-43.

29. Alharbi Z, Kauczok J, Pallua N. A review of wide surgical excision of hidradenitis suppurativa. BMC Dermatol. 2012;12:9.

30. Chen YE, Gerstle T, Verma K, Treiser MD, Kimball AB, Orgill DP. Management of hidradenitis suppurativa wounds with an internal vacuum-assisted closure device. Plast Reconst Surg. 2014;133: $370 \mathrm{e}$.

31. Bieniek A, Matusiak L, Chlebicka I, et al. Secondary intention healing in skin surgery: our own experience and expanded indications in hidradenitis suppurativa, rhinophyma and non-melanoma skin cancers. J Eur Acad Dermatol Venereol. 2013;27:1015-21.

32. Mandal A, Watson J. Experience with different treatment modules in hidradenitis suppuritiva: a study of 106 cases. Surgeon. 2005;3:23-6.

33. Ritz JP, Runkel N, Haier J, Buhr HJ. Extent of surgery and recurrence rate of hidradenitis suppurativa. Int J Color Dis. 1998;13: $164-8$.
34. Wiltz O, Schoetz Jr DJ, Murray JJ, Roberts PL, Coller JA, Veidenheimer MC. Perianal hidradenitis suppurativa: the lahey clinic experience. Dis Colon rectum. 1990;33:731-4.

35. van der Zee HH, Prens EP, Boer J. Deroofing: a tissue-saving surgical technique for the treatment of mild to moderate hidradenitis suppurativa lesions. J Am AcadDermatol. 2010;63:475-80.

36. Blok JL, Boersma M, Terra JB, et al. Surgery under general anaesthesia in severe hidradenitis suppurativa: a study of 363 primary operations in 113 patients. J Eur Acad Dermatol Venereol. 2015;29: 1590-7.

37. Hazen PG, Hazen BP. Hidradenitis suppurativa: successful treatment using carbon dioxide laser excision and marsupialization. Dermatol Surg. 2010;36:208-13.

38. Lapins J, Sartorius K, Emtestam L. Scanner-assisted carbon dioxide laser surgery: a retrospective follow-up study of patients with hidradenitis suppurativa. J Am Acad Dermatol. 2002;47:280-5.

39. Mikkelsen PR, Dufour DN, Zarchi K, et al. Recurrence rate and patient satisfaction of $\mathrm{CO} 2$ laser evapration of lesions in patients with hidradenitis suppurativa: a retrospective study. Dermatol Surg. 2015;41(2):255-60.

40. Tierney E, Mahmoud BH, Hexsel C, et al. Randomized control trial for the treatment of hidradenitis suppurativa with a neodymiumdoped yttrium aluminum garnet laser. Dermatol Surg. 2009;35: 1188-98.

41. Mahmoud BH, Tierney E, Hexsel CL, et al. Prospective controlled clinical and histopathologic study of hidradenitis suppurativa treated with the long-pulsed neodymium: yttrium-aluminum-garnet laser. J Am Acad Dermatol. 2010;62:637-45.

42. Highton L, Chan W-Y, Khwaja N, Laitung JKG. Treatment of hidradenitis suppurativa with intense pulsed light: a prospective study. Plast Reconstr Surg. 2011;128:459-65.

43. AndrewsJC SHJ, Oxman AD, et al. GRADE guidelines: 15. Going from evidence to recommendation-determinants of a recommendation's direction and strength. J Clin Epidemiol. 2013;66:726-35.

44. FDA. Structured Approach to Benefit-Risk Assessment in Drug Regulatory Decision-Making. Available at: http://www.fda.gov/ downloads/ForIndustry/UserFees/PrescriptionDrugUserFee/ UCM329758.pdf. Last accessed December 2014.

45. Kimball AB, Jemec GEB, Yang M, et al. Assessing the validity, responsiveness and meaningfulness of the hidradenitis suppurativa clinical response (HiSCR) as the clinical endpoint for hidradenitis suppurativa treatment. Br J Dermatol. 2014;171:1434-42.

46. Kimball AB, Jemec GEB, Gu Y, Williams DA. 2013 A Novel Hidradenitis Suppurativa Efficacy Variable, HiSCR (Hidradenitis Suppurativa Clinical Response), Is Responsive to Change With Adalimumab Therapy: Results of a Phase 2 Study. Presented at the 71st Annual Meeting of the American Academy of Dermatology in Miami Beach, FL, USA, March 1-5, p 6661

47. Shavit E, Dreiher J, Freud T, Halevy S, Vinker S, Cohen AD. Psychiatric comorbidities in 3207 patients with hidradenitis suppurativa. J Eur Acad Dermatol Venereol. 2015;29:371-6.

48. Kurek A, Peters EM, Chanwangpong A, Sabat R, Sterry W, Schneider-Burrus S. Profound disturbances of sexual health in patients with acne inversa. J Am Acad Dermatol. 2012;67: $422-8$. 